\section{Culturally-relevant chemistry for American Indian students}

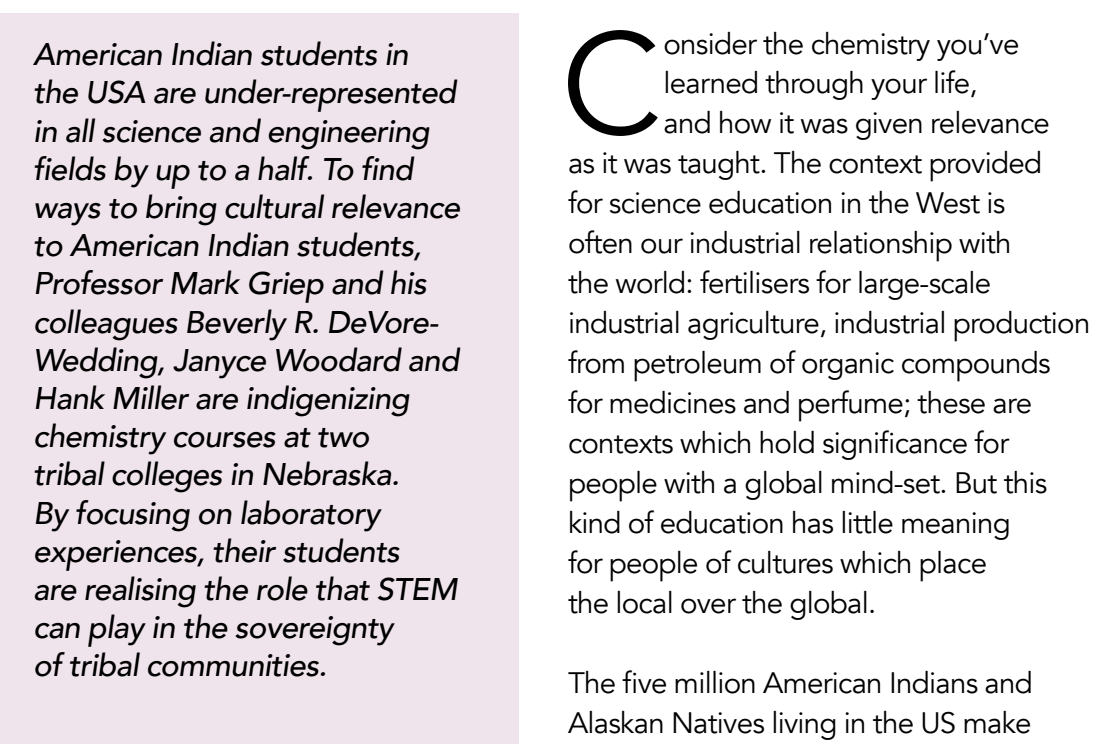

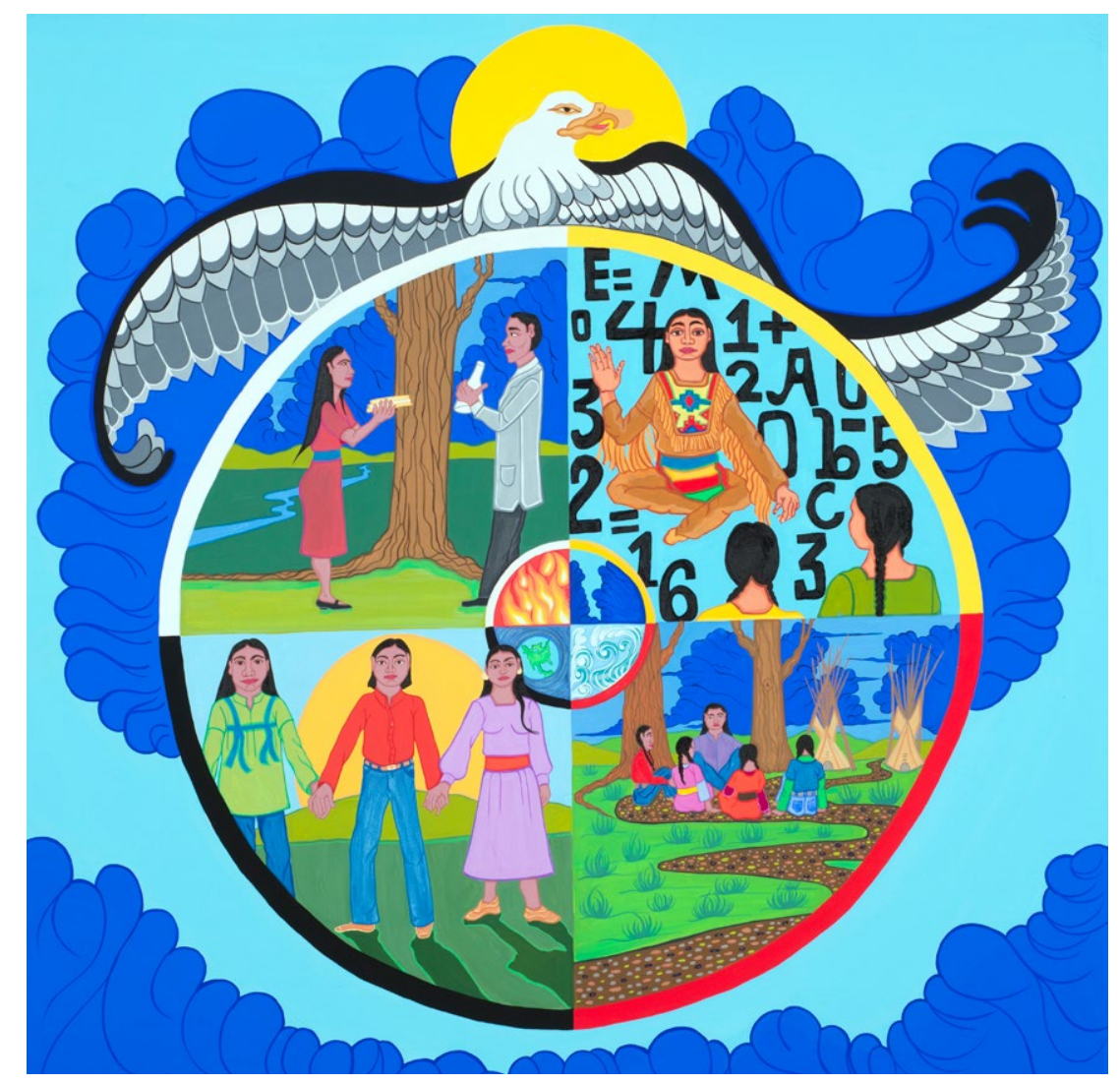

The Sharing Cycle of Scieince Learning by Laurie Houseman Whitehawk. The four aspects of the
'Framing the Chemistry Curriculum' project are placed within a Medicine Wheel, where the circle
is the cycle of life, the centre is the individual, and the cross is community. up 1.2 percent of the country's population. This incredibly significant portion of the US population are sorely underrepresented in Science, Technology, subjects in academia. In chemistry, American Indians are awarded 0.8 percent percent of PhDs. Things only get worse as you look higher up in academia. The Anemisty denstments in the US number an insubstantial eight.

For American Indians living in urban areas, participating in mainstream America, STEM skills are important for finding work: the fastest-growing career paths in the US in the last half-century require a STEM education. For those choosing to live in traditional tribal communities, STEM expertise could play a foundationa role in facilitating self-governance as US laws increasingly acknowledge tribal sovereignty. Even though the way science is taught in the US is not always relevant itself undeniably is.

INDIGENIZING CHEMISTRY COURSES Over 20,000 students attend the thirty(TCUs) across the USA. TCUs have a big role to play in providing American Indians to engage with mainstream Western laws natural resources, whilst retaining a world view which is consistent with American Indian tribal culture.

Mark A. Griep, Professor of Chemistry at the University of Nebraska-Lincoln, uses teaching methods which are culturally aware in order to sustain tribal sovereignty and strengthen American Indian culture. knowledge from local Indigenous peopl
is known as Ethnoscience, and the Engineering and Mathematics (STEM) of bachelor's degrees and only 0.6 itself undeniably is people, the science with a STEM education that allows them pertaining to land, water, air, energy and Scientific inquiry that incorporates

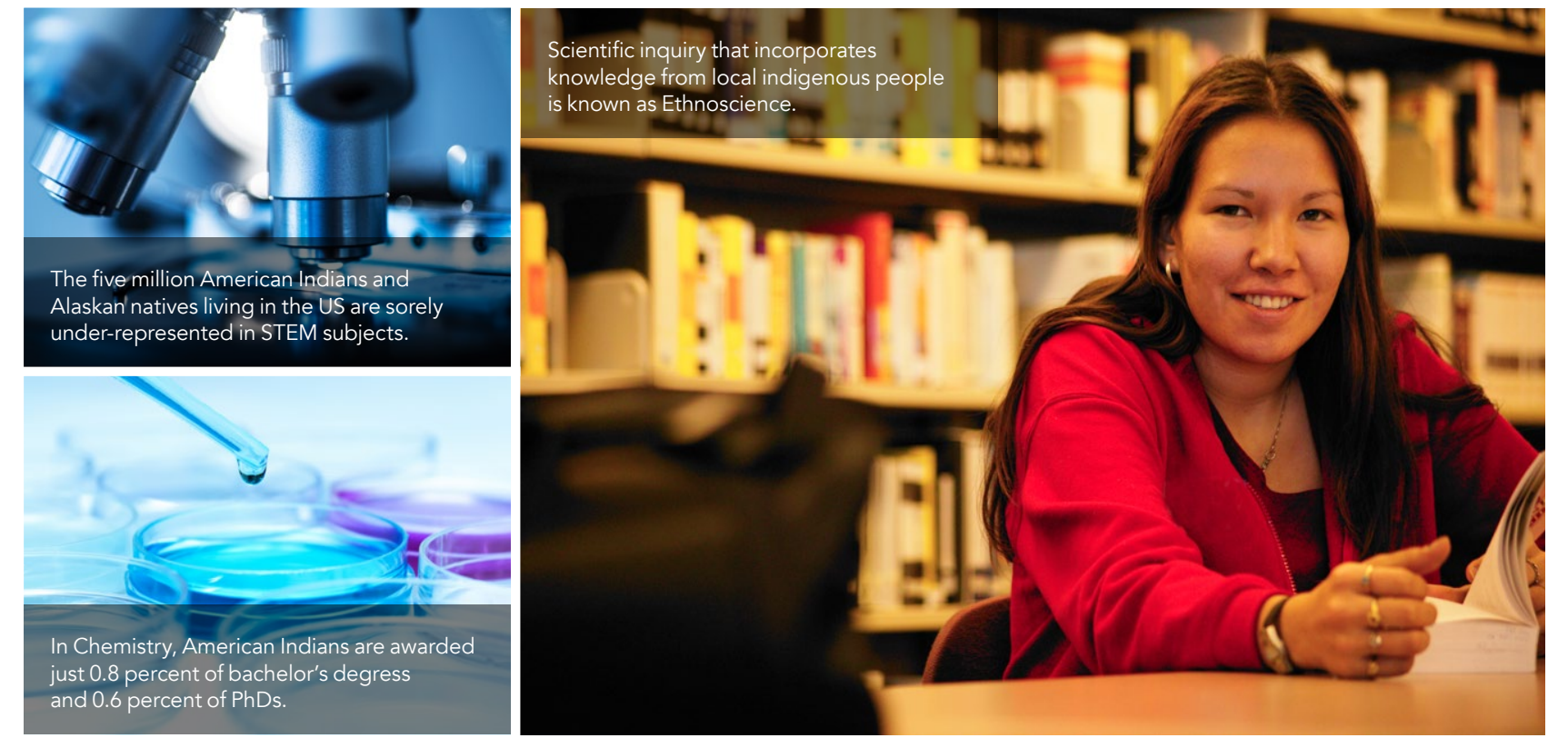

process of incorporating contexts which are relevant to American Indian culture is called Indigenizing.

\section{THE SHARING CYCLE}

The Sharing Cycle of Science Learning

is a project connecting the University

of Nebraska-Lincoln (UNL) with local

TCUs Nebraska Indian Community

College (LPTC). In his research, Professor

Griep is working on the hypothesis that

American Indian students will be more

engaged and more likely to continue in

academia when their chemical education

is indigenized. The program is designed

as year-long cycles with four parts, and is in
its sixth year. The ethnoscientific approach employed in the project is designed to engage American Indian students and everyday experience, and to benefit American Indian communities with new STEM knowledge and skills.

\section{PART 1: IDENTIFYING}

COMMUNITY TOPICS

The cycle begins with a meeting of a board of tribal leaders, college administrators, presidents of local public services, the director of the Nebraska Commission on Indian Affairs, and other members of the local scientific community. Input from tribal leaders gives science learning at the two universities context that is more likely

The first meeting of the board in 2014 established a list of community-relevant topics spanning the environment, which made the list included dlimate change, disease and air quality However, many of the issues were specific to local American Indian culture: oral histories,

griculturally-orientated culture. Before every laboratory experience across sters, a discussion is held Inking students' personal experiences ries to the

Even though the way science is taught in the US is not always relevant to American Indian people, the science itself undeniably is.

natural resources, medicinal plants and water sources are all topics which play animpotant role in the lives of local Western culture.

\section{PART 2: CHEMISTRY}

COMMUNITY CONNECTIONS

The cycle continues at the two triba colleges, where a range of indigenizing methods are employed. A laboratory manual was created which develops

the community topics into activities that are relevant both culturally and chemically For the 2014 course, only the topics in the Community Topics list with the most onto the course. By 2015, the full list was included in the manual, alongside three connections that place chemistry at the heart of daily issues.

By 2018, the manual included a wealth of links to the Missouri River tribes important to local tribal communities are incorporated; experiments may large enough that crops can be u havest for experimentation rather than us fod students are encouraged to include summarising paragraph in laboratory reports in their native languages.

For the Water Quality topic, students are given a case study on arsenic and uranium levels in water from wells of Nebraskan communities, test ten ions in water samples they have collected, and then construct a water purification unit from natural materials.

Another case study on Soil Quality provides cultural relevance through a discussion of natural nitrogen sources such as manure, urine and organic matter which can act as fertilisers for tribal

of pH and how it as well as the role 


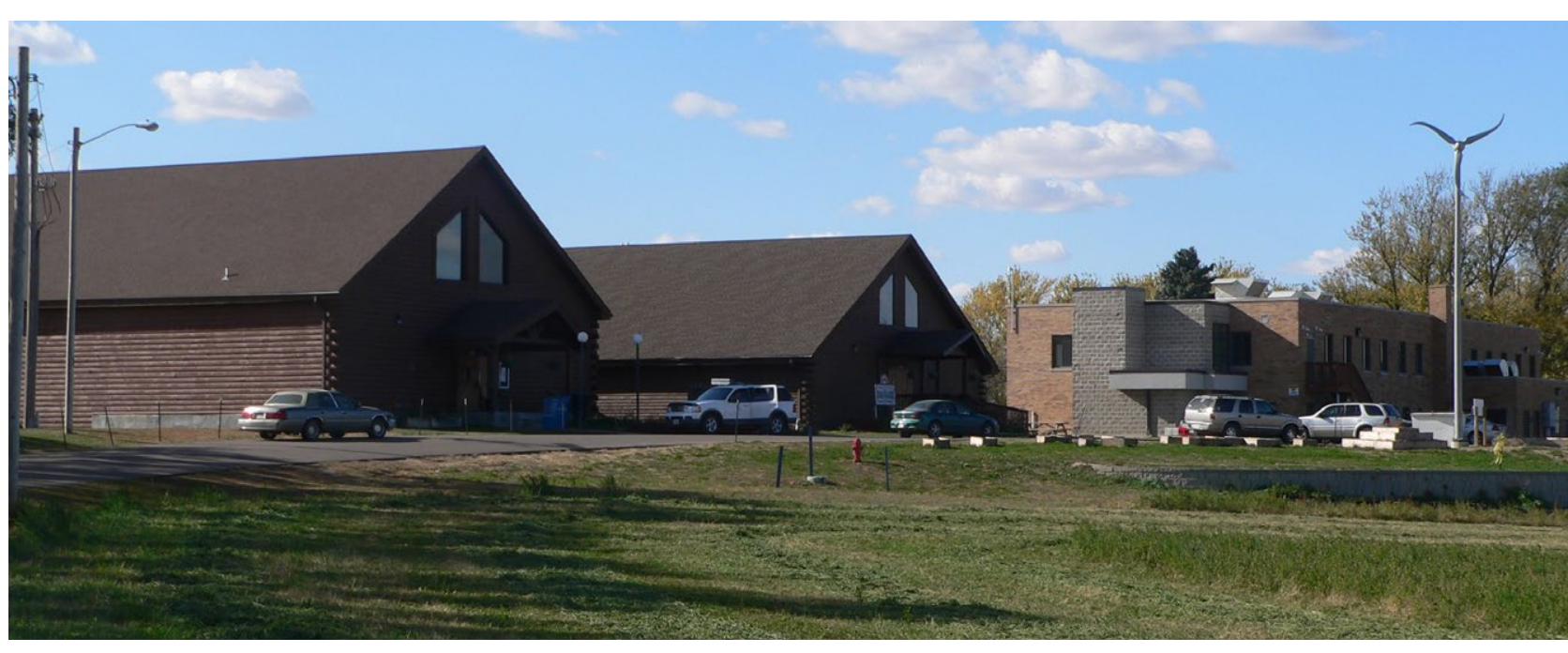

powdered limestone. Students are once again encouraged to provide their ow samples, which test
and conductivity.

\section{PART 3: DESIGNING}

A CHEMISTRY

One of the biggest issues for the project's

impact on local communities is the low

enrolment in the chemistry courses. Of the

two colleges' combined total of nearly 400

students in 2014, only six students were

enrolling on chemistry courses. A goal was

set to improve on the current enrolment

rate, and the project's focus on laboratory

experiences was chosen as an areat that
students find exciting and motivating.

Practical work is split into training and

Prica wonents so that students

understand the ambiguity of researchlevel science. In the inquiry component, students are expected to become fully hrvolved in the scientific process by that can test them instead of perorming procedural laboratory work that verifies knowledge that is established.

\section{PART 4: REVIEW}

Part four of the cycle involves a review meeting where goals are set for the next year's cycle, and to share progress through publications and outreach. As part of the outreach for this project, events are held within local tribal communites where community members environmental issues, water and food

The Sharing Cycle of Science Learning project uses a grassroots-level approach to an enormous problem in STEM education.

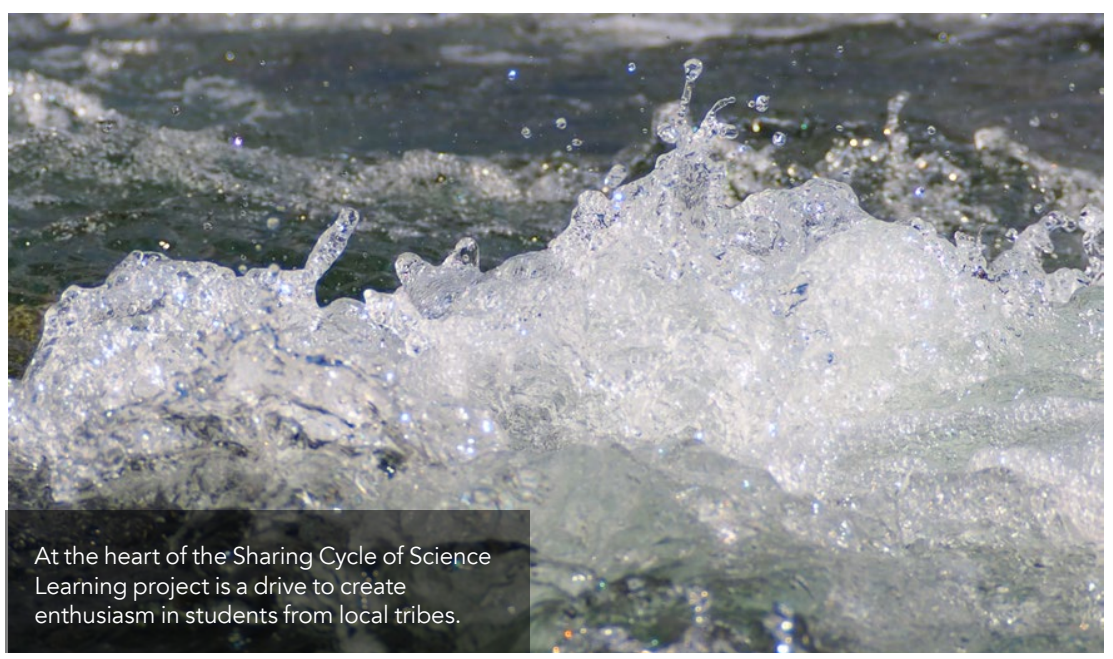

IMPACT ON COMMUNITIES Whilst increasing enrolment is an important aspect of the Sharing Cycle presce Learing, at the heart of this project is a dive to create enthusiasm to real benefits for local tribes.

One student, after testing three local water samples, discovered that water downstream of a spring contained a high level of iron ions, where upstream samples did not. She was compelled to find out more about the stream and the cause of the iron contamination. The spring, once an important source of water for her community, now contained a rusting car bonnet which she cleared from the spring. The student began exploring a career in environmental sciences, and has gone on to intern in her tribe's

For Griep and his colleagues, this is one of the most definitive examples
of how indigenised chemical earning can provide real benefit to local communities.

The Sharing Cycle of Science Learning project uses a grassroots-level approach to an enormous problem in STEM education. The under-representation of American Indians in STEM subjects is detrimental to the sovereignty of tribes across the US. The project realises the need for a community-centred approach where local communities of science educators, tribal leaders, young people and community leaders can begin to work together in a way which creats indigenized science learning through
community values and cultural relevancy

\section{Behind the Research}

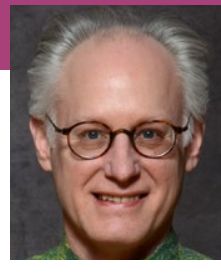

Mark

Griep

Research Objectives

Mark Griep has devoted his teaching career to finding ways to engage people to want to learn more chemistry.

\section{Detail}

736 Hamilton Hall; University of Nebraska-Lincoln; Lincoln, Nebraska 68588-0304

Janyce Woodard is Dean of STEM Initiatives at Little Priest Tribal College. Hank Miller is Math and Science Division Head and Director of Natural Resources at Webraska Indian Community College. Beverly DeVoreWedding is a postdoctoral researcher at the University of Nebraska-Lincoln. Mark Griep is Professor of Chemistry the University of Nebraska-Lincoln.

\section{Funding}

This research was supported by the National Science Foundation (Grant IA-1348382), the University of Nebrask d Nebraksa EPSCOR.

\section{Collaborators}

Beverly R. DeVore-Wedding, University of NebraskaLincoln Lincoln Nebraska, USA

- Janyce Woodard, Little Priest Tribal College, Winnebago, Nebraska, USA

Nebraska, USA

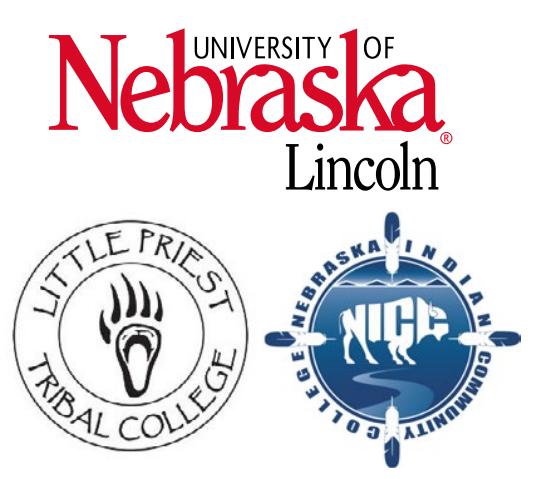

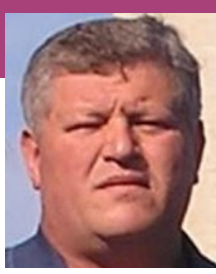

Hank

Miller

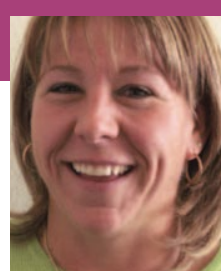

Janyce Woodard

\section{References}

Griep, Mark A., DeVore-Wedding, Beverley R., Woodard, Janyce, and Miller, Hank (2016) The Sharing Cycle of Science Learning. Great Plains Quarterly 36

Griep, Mark A., DeVore-Wedding, Beverley R., Woodard, Janyce, and Miller, Hank (2017) The Sharing Cycle of Science Learning video. NSF-sponsored STEM for All Video Showcase. https://stemforall2017.videohall.com/presentations/921

Griep, Mark A., DeVore-Wedding, Beverley R., Woodard, Janyce, and Miller, Hank (2018) Lab Manual for Connecting Chemistry to the Tribal Community: Two Semesters of Chemistry Experiments and Teachings. Lincoln, Nebraska: Keeper's Cottage Press.

DeVore-Wedding, B. R., Nicholas-Figueroa, L, Pansegrau, P., Woodard, J., Miller, H., and Griep, M. A. "Emerging Strategies for Indigenizing Science at Tribal Colleges" Wicazo Sa Review, accepted February 2019

Woodard, J, Miller, H., DeVore-Wedding, B. R., and Griep, M. A., "The Pathway to Chemical Literacy: A Resource Guide of College and Univerity Researc Joun and

\section{Personal Response}

\section{Since your award-winning paper in 2014 which} outlines the Sharing Cycle, what impact have you seen

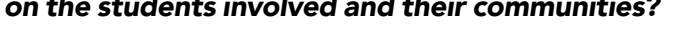

II We are pleased with the good enrolment at NICC. If it hadn't been for our partnership, these students would not have otherwise had the opportunity to take chemistry. to four-year institutions to work toward a bachelo's degree, where three of them majored in chemistry and one
in environmental science. 